\title{
Protective lung ventilation during general anesthesia: is there any evidence?
}

\author{
Silvia Coppola, Sara Froio, Davide Chiumello*
}

This article is one of ten reviews selected from the Annual Update in Intensive Care and Emergency Medicine 2014 and co-published as a series in Critical Care. Other articles in the series can be found online at http://ccforum.com/series/annualupdate2014. Further information about the Annual Update in Intensive Care and Emergency Medicine is available from http://www.springer.com/series/8901.

\section{Introduction}

In acute respiratory distress syndrome (ARDS) several studies have shown that mechanical ventilation with high tidal volume $\left(\mathrm{V}_{\mathrm{T}}\right)$ and low levels of positive endexpiratory pressure (PEEP) can promote ventilatorinduced lung injury (VILI), thus increasing morbidity and mortality [1]. An open lung strategy, combining the use of low $\mathrm{V}_{\mathrm{T}}$ with adequate PEEP levels and recruitment maneuvers, has thus been recommended in ARDS patients [2]-[4]. In patients without ARDS admitted to intensive care units (ICUs), who required mechanical ventilation for at least 12 hours, the use of a high $V_{\mathrm{T}}$ significantly increased the inflammatory response [5], [6]. In contrast to critically ill patients, during general anesthesia, mechanical ventilation is required only for a few hours, thus the beneficial effects of lung-protective ventilation remain questionable. Moreover, there are limited data from few randomized controlled trials with only small cohorts of enrolled patients.

Two recent meta-analyses that enrolled patients from ICUs and the operating room (OR) showed that lungprotective ventilation was associated with lower mortality and postoperative complications [2], [7]. However, there are no recommendations regarding optimal ventilatory strategies in patients without lung injury during general anesthesia.

In the present article, we provide a comprehensive picture of the current literature on lung-protective ventilation during general anesthesia in patients without ARDS, focusing on the applications of this strategy in patients undergoing abdominal, thoracic and cardiac surgery.

*Correspondence: chiumello@libero.it

Dipartimento di Anestesia, Rianimazione (Intensiva e Subintensiva) e Terapia del Dolore Fondazione IRCCS Ca'Granda Ospedale Maggiore Policlinico, Milan University, Milan, Italy

\section{How mechanical ventilation is applied in the operating room}

Although the protective ventilation approach may be beneficial in a broader population with and without ARDS, the use of high $V_{T}$ without PEEP is still common during general anesthesia. A large French multicenter observational study, in which more than 2,900 patients undergoing general anesthesia were enrolled, showed that $18 \%$ of patients were ventilated with a $\mathrm{V}_{\mathrm{T}}$ greater than $10 \mathrm{ml} / \mathrm{kg}$ body weight and $81 \%$ without PEEP [8]. Moreover, a recruitment maneuver was applied in only $7 \%$ of patients.

Similarly a 5-year observational study, in which 45,575 patients were enrolled, reported that although use of a $\mathrm{V}_{\mathrm{T}}$ less than $10 \mathrm{ml} / \mathrm{kg}$ and PEEP levels greater than $5 \mathrm{cmH}_{2} \mathrm{O}$ increased progressively over time, $16-18 \%$ of patients continued to receive a $\mathrm{V}_{\mathrm{T}}$ greater than $10 \mathrm{ml} / \mathrm{kg}$ without application of PEEP [9]. The presence of obesity and a short height were the main risk factors for receiving a large $\mathrm{V}_{\mathrm{T}}$ during prolonged anesthesia [10].

\section{Rationale for lung-protective ventilation during general anesthesia}

General anesthesia affects lung function primarily because of the loss of muscle tone, which promotes a reduction in lung volume, an alteration in ventilationperfusion ratio and the onset of lung atelectasis. The development of atelectasis is very common and occurs in more than $90 \%$ of subjects undergoing general anesthesia [11], [12]. Atelectasis is mainly due to three basic mechanisms [13], [14]:

- compression atelectasis

- absorption atelectasis

- loss of surfactant atelectasis.

Compression atelectasis is caused by the alterations in chest wall mechanics induced by general anesthesia per se and by several other mechanisms, such as the patient's position (head-down), the body mass index, the age of 
patient and the type of surgery (abdominal surgery or laparoscopy), which increase intra-abdominal pressure (IAP), thus decreasing chest compliance and functional residual capacity (FRC), with the consequent development of intraoperative atelectasis, intrapulmonary shunting and hypoxemia. Other factors related to surgery can contribute to the reduction in pulmonary inflation and to the development of atelectasis, such as a prolonged recumbent position intraoperatively, residual pain that reduces cough effectiveness, and postoperative diaphragmatic dysfunction that can persist for up to one week [15], [16]. If the FRC is reduced below closing capacity, airway closure will occur; consequently the lung bases will be well perfused, but underventilated due to airway closure and alveolar collapse. This phenomenon increases ventilation-perfusion mismatch and promotes further atelectasis generation and hypoxemia.

Absorption atelectasis can be caused by exposure to high inspired fraction of oxygen $\left(\mathrm{FiO}_{2}\right)$ levels. When oxygen is absorbed from the alveolar gas into the capillary in distal occluded alveolar areas or where the ventilation-perfusion ratio is low or high $\mathrm{FiO}_{2}$ levels are delivered, reabsorption of gas is promoted and generates atelectasis [11].

Loss of surfactant atelectasis arises from alterations in surfactant induced by effects of general anesthesia on healthy lungs [17].

The presence of atelectasis is an important factor in the pathogenesis of postoperative pulmonary complications, such as hypoxemia, pulmonary infections and local inflammatory response [18]. Postoperative pulmonary complications in the first hours after surgery are mainly due to atelectasis in the dependent regions of the lungs. Lung atelectasis may also promote the development of VILI by lung overdistension and by cyclic opening and closing of lung units at the boundary between the normally inflated and collapsed lung units. On the basis of several studies of mechanical ventilation in ARDS patients, the same mechanisms of injury could be applied to mechanically ventilated patients during general anesthesia with healthy lungs. The use of recruitment maneuvers associated with adequate levels of PEEP could open and keep open previously collapsed lung regions. In addition, the use of a low-moderate $\mathrm{V}_{\mathrm{T}}$ could avoid overstress-overdistension of lung units.

\section{Protective versus conventional lung ventilation strategies during general anesthesia}

In Table 1, we provide a synopsis of randomized controlled trials (RCT) comparing protective versus conventional lung ventilation strategies during general anesthesia over time, in specific surgical settings showing the main outcomes explored in these studies. In Figure 1, we show the numbers of RCTs that we considered, divided according to the type of surgery.

\section{Abdominal surgery}

Postoperative pulmonary complications remain a significant problem after surgery. They occur in 5-10\% of all surgical patients and 9-40 \% of those undergoing abdominal surgery experience postoperative pulmonary complications [19], which increase morbidity and mortality [19], [20]. Among the postoperative pulmonary complications, lung atelectasis is one of the principle mechanisms for the development of VILI, pneumonia and postoperative respiratory failure.

In this context, Wrigge and colleagues investigated in two studies the effect of different ventilatory strategies on the release of inflammatory mediators in patients undergoing elective surgery [21], [22]. In the first study, 39 patients scheduled for extra-thoracic surgery (abdominal, vascular, bone and other) were randomized to one of three mechanical ventilation strategies: 1) $V_{T}$ of $15 \mathrm{ml} / \mathrm{kg}$ ideal body weight without PEEP; 2) $\mathrm{V}_{\mathrm{T}}$ of $6 \mathrm{ml} /$ $\mathrm{kg}$ without PEEP; and 3) $\mathrm{V}_{\mathrm{T}}$ of $6 \mathrm{ml} / \mathrm{kg}$ with PEEP $10 \mathrm{cmH}_{2} \mathrm{O}$. Plasma levels of interleukin (IL)-6, IL-10 and tumor necrosis factor (TNF)- $\alpha$ were measured after one hour of mechanical ventilation [21]. In the second study, 64 patients undergoing general anesthesia were randomized to receive mechanical ventilation with a $V_{T}$ of $12-$ $15 \mathrm{ml} / \mathrm{kg}$ ideal body weight without PEEP, or with $\mathrm{V}_{\mathrm{T}}$ of $6 \mathrm{ml} / \mathrm{kg}$ and PEEP levels of $10 \mathrm{cmH}_{2} \mathrm{O}$. Local and systemic inflammatory biomarkers, including IL-8, IL-1, IL-6, IL10 , TNF- $\alpha$ and IL-12, were determined after 3 hours of mechanical ventilation [22]. Both studies were unable to find any significant differences in terms of inflammatory mediators and the authors concluded that, in contrast to patients with acute lung injury in whom there is a systemic inflammatory reaction during major surgery, in uninjured normal lungs short term mechanical ventilation alone with high $V_{T}$ levels did not increase pulmonary or systemic inflammation related to surgery [21], [22]. No differences in biomarkers of lung epithelial injury were observed after 5 hours in a later study, which compared ventilation with $\mathrm{V}_{\mathrm{T}} 12 \mathrm{ml} / \mathrm{kg}$ ideal body weight without PEEP versus $\mathrm{V}_{\mathrm{T}} 6 \mathrm{ml} / \mathrm{kg}$ and PEEP $10 \mathrm{cmH}_{2} \mathrm{O}$ [23].

To explore the effect of a high compared to a low $\mathrm{V}_{\mathrm{T}}$ for similar PEEP levels, Treschan et al. randomized patients to receive a $V_{T}$ of $12 \mathrm{ml} / \mathrm{kg}$ body weight versus $6 \mathrm{ml} / \mathrm{kg}$ with a PEEP of $5 \mathrm{cmH}_{2} \mathrm{O}$ [24]. Except for the intraoperative oxygenation, which was higher in the high $\mathrm{V}_{\mathrm{T}}$ group, there was no significant difference in forced vital capacity and forced expiratory volume in one second between groups, for up to five days after the surgery.

Different from the previous studies, Weingarten et al. evaluated an open lung strategy in which low $\mathrm{V}_{\mathrm{T}}$ ventilation was associated with PEEP plus a recruitment maneuver in order to minimize atelectasis and shear stress in the lung parenchyma [25]. This open lung 
Table 1 Synopsis of randomized controlled trials comparing protective versus conventional lung ventilation strategy during general anesthesia. Studies are grouped according to specific surgical settings: abdominal, thoracic and cardiac surgery

\begin{tabular}{|c|c|c|c|c|c|c|c|c|c|c|}
\hline & \multirow[b]{3}{*}{ First author [ref] } & \multirow[b]{3}{*}{ Year } & \multirow[b]{3}{*}{$\mathrm{N}^{\circ}$ pts } & \multicolumn{6}{|c|}{ Ventilatory strategy } & \multirow[b]{3}{*}{ Outcomes } \\
\hline & & & & \multicolumn{2}{|c|}{$\underset{(\mathrm{ml} / \mathrm{kg})}{\mathrm{V}_{\mathrm{T}}}$} & \multicolumn{2}{|c|}{$\begin{array}{c}\text { PEEP } \\
\left(\mathrm{cmH}_{2} \mathrm{O}\right)\end{array}$} & \multicolumn{2}{|c|}{$\begin{array}{l}\text { Recruitment } \\
\text { maneuver } \\
\text { (Yes/No) }\end{array}$} & \\
\hline & & & & Case & Control & Case & Control & Case & Control & \\
\hline \multirow[t]{8}{*}{ Abdominal } & Wrigge [21] & 2000 & 39 & $\begin{array}{c}66 \\
6\end{array}$ & 15 & $\begin{array}{c}0 \\
10\end{array}$ & 0 & No & No & Systemic IL-6, IL-10, TNF-a: similar \\
\hline & Wrigge [22] & 2004 & 30 & 6 & $12-15$ & 10 & 0 & No & No & $\begin{array}{l}\text { Systemic/pulmonary IL-8-1-6-10-12, TNF-a: } \\
\text { similar }\end{array}$ \\
\hline & Determann [23] & 2008 & 40 & 6 & 12 & 10 & 0 & No & No & Lung epithelial injury biomarkers: similar \\
\hline & Weingarten [25] & 2010 & 40 & 6 & 10 & 12 & 0 & Yes & No & $\begin{array}{l}\text { Intraoperative } \mathrm{PaO}_{2^{\prime}} \text { Lung mechanics: better } \\
\text { Systemic IL-8, IL-6: similar }\end{array}$ \\
\hline & Treschan [24] & 2012 & 101 & 6 & 12 & 5 & 5 & No & No & Postoperative dynamic spirometry: similar \\
\hline & Severgnini [26] & 2013 & 56 & 7 & 9 & 10 & 0 & Yes & No & $\begin{array}{l}\text { Clinical Pulmonary Infection Score: lower } \\
\text { Postoperative respiratory function: better }\end{array}$ \\
\hline & Futier [27] & 2013 & 400 & $6-8$ & $10-12$ & $6-8$ & 0 & Yes & No & $\begin{array}{l}\text { Pulmonary/extrapulmonary complications: } \\
\text { lower } \\
\text { Hospital stay: shorter }\end{array}$ \\
\hline & PROVHILO [28] & - & 900 & $<8$ & $<8$ & 12 & $\leq 2$ & Yes & No & Postoperative pulmonary complications \\
\hline \multirow[t]{3}{*}{ Thoracic } & Schilling [33] & 2005 & 32 & 5 & 10 & 0 & 0 & No & No & Pulmonary TNF-a, IL-8, IL-10: lower TNF-a \\
\hline & Michelet [36] & 2006 & 52 & 5 & 9 & 5 & 0 & No & No & $\begin{array}{l}\text { Systemic IL-1 } \beta \text {, IL-6, IL-8: lower } \\
\text { Oxygenation: better } \\
\text { Postoperative MV length: shorter }\end{array}$ \\
\hline & Yang [35] & 2011 & 100 & 6 & 10 & 5 & 0 & No & No & $\begin{array}{l}\text { Oxygenation: better } \\
\text { Postoperative pulmonary complications: lower }\end{array}$ \\
\hline \multirow[t]{7}{*}{ Cardiac } & Chaney [49] & 2000 & 25 & 6 & 12 & 5 & 5 & No & No & Postoperative lung mechanics: better \\
\hline & Koner [42] & 2004 & 44 & 6 & $\begin{array}{l}10 \\
10\end{array}$ & 5 & $\begin{array}{l}0 \\
5\end{array}$ & No & No & $\begin{array}{l}\text { Systemic IL-6, TNF-a: similar } \\
\text { Hospital LOS: similar } \\
\text { Postoperative pulmonary function: similar }\end{array}$ \\
\hline & Zupancich [44] & 2005 & 40 & 8 & $10-12$ & 10 & $2-3$ & No & No & Pulmonary and systemic II-6, IL-8: lower \\
\hline & Reis [47] & 2005 & 62 & $4-6$ & $6-8$ & 10 & 5 & Yes & No & $\begin{array}{l}\text { Systemic II-8, IL-10: lower } \\
\text { Systemic IL-6, TNF-a, IFN-ץ: similar }\end{array}$ \\
\hline & Reis [48] & 2005 & 69 & $4-6$ & $6-8$ & 10 & 5 & Yes & No & $\begin{array}{l}\text { Postoperative hypoxemia: lower } \\
\text { Postoperative FRC: better }\end{array}$ \\
\hline & Wrigge [41] & 2005 & 44 & 6 & 12 & $9^{*}$ & $7^{*}$ & No & No & $\begin{array}{l}\text { Systemic TNF-a, IL-6-8-2-4-10: similar } \\
\text { Pulmonary TNF-a, IL-6-8-2-4-10: lower TNF-a }\end{array}$ \\
\hline & Sundar [43] & 2011 & 149 & 6 & 10 & $5^{*}$ & $4.9^{*}$ & No & No & $\begin{array}{l}\text { Time to extubation: similar } \\
\text { Extubation at 6-8 h after surgery: better } \\
\text { Reintubation: lower }\end{array}$ \\
\hline
\end{tabular}

Case: lung-protective ventilation group; Control: conventional ventilation strategy group. Outcome results always refer to the case group. In the Thoracic surgery section, ventilatory parameters refer to one-lung ventilation. *PEEP levels set according to ARDSnetwork strategy. $V_{\text {. }}$ t tidal volume; PEEP: positive end-expiratory pressure; MV: mechanical ventilation; FRC: functional residual capacity; IL: interleukin; TNF: tumor necrosis factor; IFN: interferon; pts: patients; PaO : partial pressure of oxygen in arterial blood; LOS: length of stay.

strategy, consisting of a $\mathrm{V}_{\mathrm{T}}$ of $6 \mathrm{ml} / \mathrm{kg}$ predicted body weight with PEEP $12 \mathrm{cmH}_{2} \mathrm{O}$ and recruitment maneuvers, significantly improved only intraoperative oxygenation with no difference in the inflammatory response or length of hospital stay compared to a $\mathrm{V}_{\mathrm{T}}$ of $10 \mathrm{ml} / \mathrm{kg}$ without PEEP [25]. These first studies seem to suggest that a protective ventilator strategy does not have any role in patients without lung injury [21]-[25]. However, these studies demonstrated that this mode of ventilation is feasible in open abdominal surgery with no adverse effects [23], [25]. In contrast to the previous studies, Severgnini et al., comparing a lung protective mechanical ventilation consisting of a $\mathrm{V}_{\mathrm{T}}$ of $7 \mathrm{ml} / \mathrm{kg}$ ideal body weight with PEEP levels of $10 \mathrm{cmH}_{2} \mathrm{O}$ and recruitment maneuvers versus a $\mathrm{V}_{\mathrm{T}}$ of $9 \mathrm{ml} / \mathrm{kg}$ without PEEP, showed beneficial effects of the lung-protective strategy during general anesthesia lasting more than 2 hours [26]. The lung-protective strategy improved postoperative 


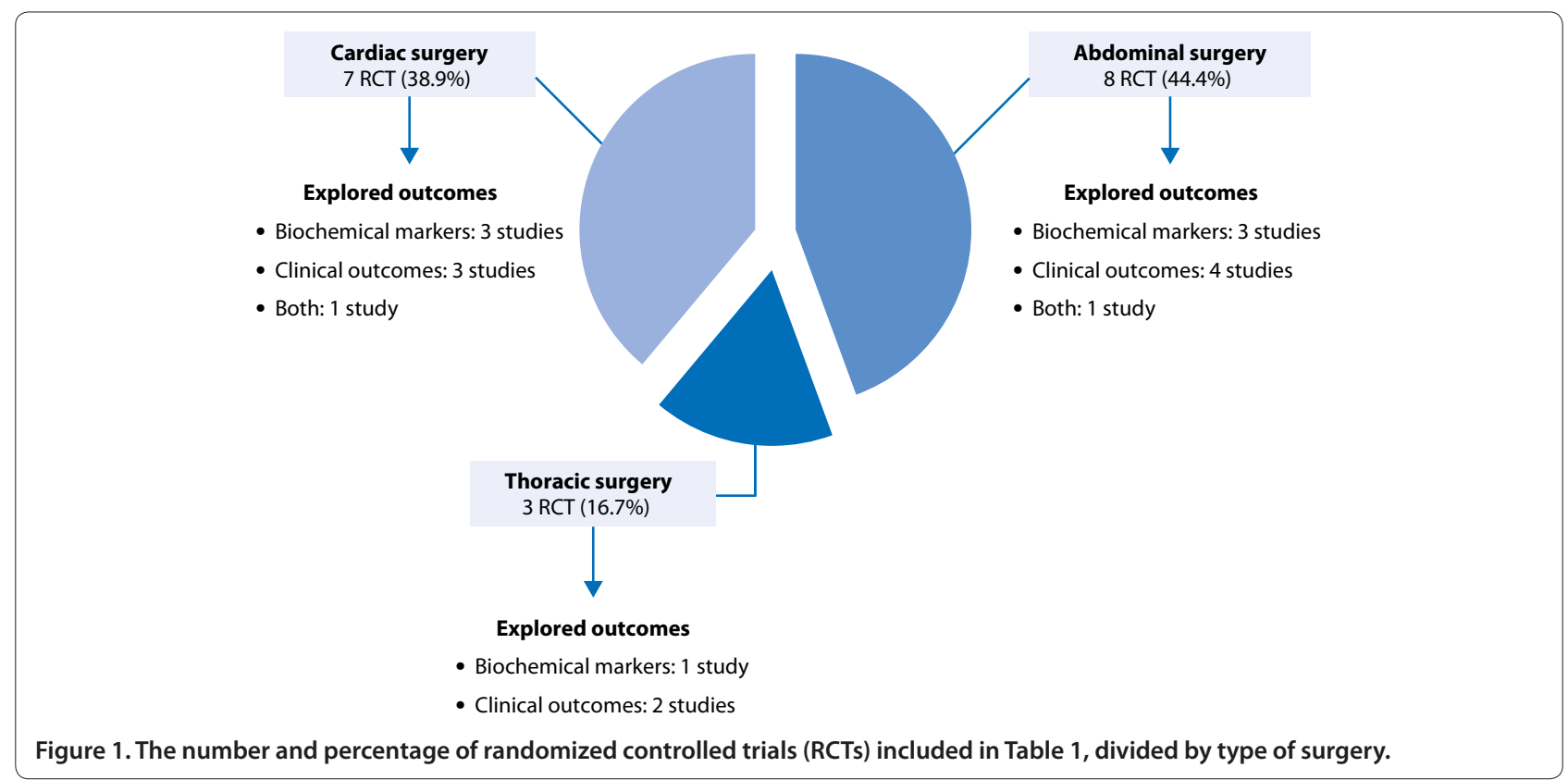

respiratory function in terms of dynamic spirometry, oxygenation, and pulmonary complications for up to 5 days after surgery, without increasing the incidence of intraoperative complications. Although there was no significant difference in the hospital length of stay between groups, $20 \%$ of the patients in the lungprotective group, compared with $40 \%$ in the control group, were still in hospital on postoperative day 14 [26].

A recent multicenter randomized clinical trial in which lung-protective ventilation with a $\mathrm{V}_{\mathrm{T}}$ of $6-8 \mathrm{ml} / \mathrm{kg}$ predicted body weight, PEEP 6-8 $\mathrm{cmH}_{2} \mathrm{O}$ and recruitment maneuvers repeated every 30 minutes was compared with non-protective ventilation with $\mathrm{V}_{\mathrm{T}}$ 10$12 \mathrm{ml} / \mathrm{kg}$ without PEEP, found that the lung-protective ventilation significantly reduced major pulmonary and extrapulmonary complications from $27.5 \%$ to $10.5 \%$ [27]. The lung-protective strategy also significantly reduced the proportion of patients who required postoperative ventilator assistance from $17 \%$ to $5 \%$ and the hospital length of stay.

Compared to the earlier studies [22]-[25], these two recent trials found a beneficial effect of a lung-protective strategy probably because of the large number of enrolled patients, the homogeneity of the selected population of patients undergoing open abdominal surgery with an expected duration of at least 2 hours, the standardization of fluid management, and the clinically relevant outcomes explored (not only lung inflammatory mediators) in the postoperative period.

These results demonstrate that in patients undergoing abdominal surgery a multifaceted open lung protective strategy can prevent the intraoperative alveolar opening and closing and overdistension of lung areas that lead to VILI and pulmonary complications. Currently, we are waiting for the results of the PROVHILO study, a worldwide multicenter RCT in which patients scheduled for abdominal surgery are being enrolled. In this study, all patients are ventilated with protective tidal volumes (in both groups, $\mathrm{V}_{\mathrm{T}}<8 \mathrm{ml} / \mathrm{kg}$ predicted body weight) and randomly assigned to a lung-protective strategy with use of recruitment maneuvers and PEEP levels of $12 \mathrm{cmH}_{2} \mathrm{O}$ or a conventional strategy without recruitment maneuvers and PEEP between 0 and $2 \mathrm{cmH}_{2} \mathrm{O}$ [28]. If the results of this study confirm those of the last two trials [27], [26], lung-protective strategies will be more widely applied in patients undergoing abdominal surgery [28].

\section{Thoracic surgery}

During thoracic surgery, one-lung ventilation is an established procedure that could increase the risk of promoting VILI compared to double lung ventilation, because of greater reduction in lung volume and greater degree of alveolar collapse in dependent lung regions. Two retrospective studies of patients who had undergone elective pneumonectomy found that larger intraoperative $\mathrm{V}_{\mathrm{T}}$ and higher inspiratory airway pressure were associated with the development of pulmonary edema and respiratory failure [29], [30]. Despite this, conventional mechanical ventilation in these patients consists of $\mathrm{V}_{\mathrm{T}}$ between $8-12 \mathrm{ml} / \mathrm{kg}$ to prevent lung atelectasis with zero or low levels of PEEP to avoid shunt aggravation by redistribution of blood flow to non-ventilated regions [31], [32]. However this approach is not an evidencebased guideline. 
Schilling et al., in a randomized study in patients scheduled for open thoracic surgery undergoing onelung ventilation, showed that mechanical ventilation with $\mathrm{V}_{\mathrm{T}}$ of $5 \mathrm{ml} / \mathrm{kg}$ ideal body weight compared to $10 \mathrm{ml} / \mathrm{kg}$ significantly decreased the pulmonary inflammatory response up to 2 hours postoperatively [33]. Subsequently, Licker et al. retrospectively evaluated the implementation of a lung-protective ventilation strategy in lung cancer resection combining a low $\mathrm{V}_{\mathrm{T}}(<8 \mathrm{ml} / \mathrm{kg})$ with PEEP 4-10 $\mathrm{cmH}_{2} \mathrm{O}$ and recruitment maneuvers versus a conventional $\mathrm{V}_{\mathrm{T}}$ target ventilation of 9-12 ml/ kg during two-lung ventilation and $8-10 \mathrm{ml} / \mathrm{kg}$ during onelung ventilation without recruitment maneuvers and PEEP applied at the discretion of the anesthetist [34]. The lung-protective strategy significantly reduced the incidence of atelectasis (from $8.8 \%$ to $5 \%$ ), postoperative acute lung injury (from $3.7 \%$ to $0.9 \%$ ), ICU admission (from $9.4 \%$ to $2.5 \%$ ) and length of hospital stay (from $14.5 \pm 3.3$ to $11.8 \pm 4.1$ days). These data were confirmed in a randomized study during elective lobectomy in which patients were ventilated with a high $\mathrm{V}_{\mathrm{T}}$ of $10 \mathrm{ml} / \mathrm{kg}$ without PEEP compared to a low $\mathrm{V}_{\mathrm{T}}$ of $6 \mathrm{ml} / \mathrm{kg}$ with $5 \mathrm{cmH}_{2} \mathrm{O}$ of PEEP and pressure controlled ventilation [35]. The lung-protective ventilation was associated with a lower incidence of lung infiltration or atelectasis (2 versus 10) and of cases of hypoxemia (1 versus 8 ).

During esophagectomy, a procedure requiring a prolonged period of one-lung ventilation, Michelet et al. demonstrated in an RCT that lung-protective ventilation $\left(\mathrm{V}_{\mathrm{T}} 9 \mathrm{ml} / \mathrm{kg}\right.$ during two-lung ventilation, reduced to $5 \mathrm{ml} /$ $\mathrm{kg}$ during one-lung ventilation and PEEP $5 \mathrm{cmH}_{2} \mathrm{O}$ throughout the operative time) could prevent alterations in lung function and reduce the inflammatory response in patients without previous lung disease compared to conventional ventilation strategy $\left(\mathrm{V}_{\mathrm{T}} 9 \mathrm{ml} / \mathrm{kg}\right.$ during twoand one-lung ventilation without PEEP) [36].

The majority of studies so far have demonstrated that, during thoracic surgery, traditional intraoperative ventilatory settings seem to be harmful. An intraoperative open lung approach based on small $\mathrm{V}_{\mathrm{T}}$, moderate-high PEEP and recruitment maneuvers may be beneficial but further randomized clinical trials are necessary to generate clinical evidence.

\section{Cardiac surgery}

In cardiac surgery, use of cardiopulmonary bypass (CPB), contact of the blood with artificial surfaces and ischemia/ reperfusion of the heart and lungs are associated with a pulmonary and systemic inflammatory response, with activation of elements of the complement cascade, neutrophils and pro-inflammatory cytokines [37]-[39]. This systemic inflammatory response syndrome can be mild to severe in 10 to $35 \%$ of cases and may induce an acute lung injury, which generally resolves within
24 hours. This clinical event contributes to increased morbidity and mortality [40]. In this context, injurious mechanical ventilation could aggravate the primary inflammatory response described above (first hit), representing a second hit. Moreover, during $\mathrm{CPB}$, the lungs are not ventilated and either rest at low values of continuous positive pressure [41] or are completely disconnected from the ventilator [42]-[44]. Traditionally, ventilator settings in cardiac surgery patients included large $\mathrm{V}_{\mathrm{T}}(10-15 \mathrm{ml} / \mathrm{kg})$ in order to minimize atelectasis and minimal levels of PEEP to reduce hemodynamic consequences. Following the results of clinical trials in ARDS patients [45], [46], there has been increased interest in protective lung ventilatory strategies during cardiac anesthesia and several trials have tried to demonstrate the role of protective lung ventilation in this context.

Koner et al. found no differences in plasma levels of IL- 6 and TNF- $\alpha 2$ hours after the end of CBP among patients randomized to receive protective ventilation $\left(\mathrm{V}_{\mathrm{T}}\right.$ $6 \mathrm{ml} / \mathrm{kg}$ ideal body weight, PEEP $5 \mathrm{cmH}_{2} \mathrm{O}$ ) or conventional $\mathrm{V}_{\mathrm{T}}$ ventilation $\left(\mathrm{V}_{\mathrm{T}} 10 \mathrm{ml} / \mathrm{kg}\right)$ with and without PEEP levels at $5 \mathrm{cmH}_{2} \mathrm{O}$ [42]. There were no differences among groups in the explored clinical outcomes, including total intraoperative fluid balance, intubation time and hospital length of stay [42].

Wrigge et al. measured pulmonary and plasma levels of different cytokines and chemokines (IL-2, IL-4, IL-6, IL-8, IL-10, TNF- $\alpha$ and interferon- $\gamma$ ) in patients ventilated with high or with low tidal volumes $\left(\mathrm{V}_{\mathrm{T}} 12 \mathrm{ml} / \mathrm{kg}\right.$ versus $\mathrm{V}_{\mathrm{T}} 6 \mathrm{ml} / \mathrm{kg}$ ideal body weight). They observed higher values of TNF- $\alpha$ after 6 hours of ventilation with high $V_{T}$, with no differences in other inflammatory mediators [41].

However, a significantly reduced inflammatory response, in terms of pulmonary and systemic mediator levels (IL-6 and IL-8) was observed when applying a moderate PEEP level strategy $\left(\mathrm{V}_{\mathrm{T}} 8 \mathrm{ml} / \mathrm{kg}\right.$ with PEEP $10 \mathrm{cmH}_{2} \mathrm{O}$ ) compared to a low PEEP and high $\mathrm{V}_{\mathrm{T}}$ strategy (10-12 $\mathrm{ml} / \mathrm{kg}$ with PEEP 2-3 $\left.\mathrm{cmH}_{2} \mathrm{O}\right)$ [44]. In comparison to previous studies [41], [42], this study evaluated a greater difference in PEEP levels and a longer duration of mechanical ventilation [44].

Reis et al. investigated the effect of open lung ventilation, consisting of low $\mathrm{V}_{\mathrm{T}}(4-6 \mathrm{ml} / \mathrm{kg})$ with moderatehigh PEEP levels $\left(10 \mathrm{cmH}_{2} \mathrm{O}\right)$ and recruitment maneuvers, on inflammatory mediators. In this study, they compared an early (immediately after intubation) and a late (at the end of $\mathrm{CPB}$ ) application of the same open lung strategy, with conventional ventilation $\left(\mathrm{V}_{\mathrm{T}} 6-8 \mathrm{ml} / \mathrm{kg}\right.$, PEEP $5 \mathrm{cmH}_{2} \mathrm{O}$ ). Both the open lung approaches significantly decreased IL-8 and IL-10 levels after CPB [47]. Subsequently, the same authors showed that the early open lung approach significantly attenuated the reduction in postoperative FRC, for up to 5 days after surgery, 
and reduced the incidence of hypoxemic events during the first 3 days after extubation [48]. Ventilation and weaning times were similar among groups. This positive effect on postoperative FRC could be related to the prevention of additional lung injury caused by mechanical ventilation. Chaney et al. similarly reported better dynamic and static lung compliance and less shunt in patients ventilated with low compared to high $\mathrm{V}_{\mathrm{T}}$ (6 versus $12 \mathrm{ml} / \mathrm{kg}$ ) [49].

Recently Sundar and colleagues observed that a larger number of patients were extubated after 8 hours (53\% versus $31 \%$ ) when ventilated with a low $\mathrm{V}_{\mathrm{T}}$ of $6 \mathrm{ml} / \mathrm{kg}$ ideal body weight compared to $\mathrm{V}_{\mathrm{T}} 10 \mathrm{ml} / \mathrm{kg}$ with similar PEEP levels. Furthermore, a lower postoperative reintubation rate was observed. However, global time to extubation was similar between groups, as were ICU length of stay and 28-day mortality [43].

There is, therefore, a small amount of evidence from small studies in support of lung-protective ventilation in cardiac surgery patients [50]. However, the presence of several confounding factors, not related to mechanical ventilation, which could contribute to the development of a systemic inflammatory response and postoperative pulmonary complications, may have influenced the main outcome results. Hence, further studies with larger cohorts of patients are needed to confirm the still weak evidence in favor of lung-protective ventilation in cardiac anesthesia.

\section{Conclusions}

Mechanical ventilation is necessary for patients during general anesthesia. Although mechanical ventilation is considered a safe procedure, it can generate pulmonary stress and strain, promoting lung injury. There is increasing evidence that lung-protective ventilation may be beneficial in abdominal surgery (lower inflammatory response and better outcome). During thoracic and cardiac surgery, lung protective ventilation has only been associated with a reduced inflammatory response.

Lung-protective ventilation should be considered in the presence of pulmonary disease, prolonged anesthesia, in high-risk patients or for high-risk surgery. Although lung-protective ventilation may be beneficial for the lung, it may impair the cardiovascular system, reducing venous return and cardiac output and requiring the use of fluids and vasopressors. Thus, the risks and benefits of lungprotective ventilation need to be balanced in each individual patient.

\section{List of abbreviations used}

ARDS: acute respiratory distress syndrome; $\mathrm{FiO}_{2}$ : inspired fraction of oxygen; FRC: functional residual capacity; IAP: intra-abdominal pressure; IFN: interferon; IL: interleukin; LOS: length of stay; MV: mechanical ventilation; OR: operating room; PEEP: positive end-expiratory pressure; $\mathrm{PaO}_{2}$ : partial pressure of oxygen in arterial blood; pts: patients; RCT: randomized controlled trials; TNF: tumor necrosis factor; $\mathrm{VILI}$ : ventilator-induced lung injury; $\mathrm{V}_{\mathrm{T}}$ : tidal volume.
Competing interests

The authors declare that they have no competing interests.

\section{Declarations}

The publication costs of the article were covered by the corresponding auithor's institution.

Published: 18 March 2014

\section{References}

1. Plotz FB, Slutsky AS, van Vught AJ, Heijnen CJ: Ventilator-induced lung injury and multiple system organ failure: a critical review of facts and hypotheses. Intensive Care Med 2004, 30:1865-1872.

2. Serpa NA, Cardoso SO, Manetta JA, Pereira VG, Espósito DC: Pasqualucci Mde O, Damesceno MC < Schultz MJ: Association between use of lungprotective ventilation with lower tidal volumes and clinical outcomes among patients without acute respiratory distress syndrome: a metaanalysis. JAMA 2012, 308:1651-1659.

3. De Prost N, Dreyfuss D: How to prevent ventilator-induced lung injury? Minerva Anestesio/ 2012, 78:1054-1066.

4. Bernard GR, Artigas A, Brigham KL, Carlet J, Falke K, Hudson L, Lamy M, Legall $J R$, Morris A, Spragg E: The American-European Consensus Conference on ARDS. Definitions, mechanisms, relevant outcomes, and clinical trial coordination. Am J Respir Crit Care Med 1994, 149:818-824.

5. Pinheiro DO, Hetzel MP, dos Anjos SM, Dallegrave D, Friedman G: Mechanical ventilation with high tidal volume induces inflammation in patients without lung disease. Crit Care 2010, 14:R39.

6. Determann RM, Royakkers A, Wolthuis EK, Vlaar AP, Choi G, Paulus F, Hofstra JJ, de Graaf MJ, Korevaar JC, Schultz MJ:Ventilation with lower tidal volumes as compared with conventional tidal volumes for patients without acute lung injury: a preventive randomized controlled trial. Crit Care 2010, 14:R1.

7. Hemmes SN, Serpa NA, Schultz MJ: Intraoperative ventilatory strategies to prevent postoperative pulmonary complications: a meta-analysis. Curr Opin Anaesthesiol 2013, 26:126-133.

8. Jaber S, Coisel Y, Chanques G, Futier E, Constantin JM, Michelet P, Beaussier M, Lefrant JY, Allaouchiche B, Capdevila X, Marret E: A multicentre observational study of intra-operative ventilatory management during general anaesthesia: tidal volumes and relation to body weight. Anaesthesia 2012, 67:999-1008.

9. Hess DR, Kondili D, Burns E, Bittner EA, Schmidt UH: A 5-year observational study of lung-protective ventilation in the operating room: A singlecenter experience. J Crit Care 2013, 28:533-533.

10. Fernandez-Bustamante A, Wood CL, Tran ZV, Moine P: Intraoperative ventilation: incidence and risk factors for receiving large tidal volumes during general anesthesia. BMC Anesthesiol 2011, 11:22.

11. Duggan M, Kavanagh BP: Pulmonary atelectasis: a pathogenic perioperative entity. Anesthesiology 2005, 102:838-854.

12. Cai H, Gong H, Zhang L, Wang Y, Tian Y: Effect of low tidal volume ventilation on atelectasis in patients during general anesthesia: a computed tomographic scan. J Clin Anesth 2007, 19:125-129.

13. Joyce $C J$, Williams $A B$ : Kinetics of absorption atelectasis during anesthesia: a mathematical model. J Appl Physiol 1999, 86:1116-1125.

14. Hedenstierna G, Rothen HU: Atelectasis formation during anesthesia: causes and measures to prevent it. J Clin Monit Comput 2000, 16:329-335.

15. Simonneau G, Vivien A, Sartene R, Kustlinger F, Samii K, Noviant Y, Duroux P: Diaphragm dysfunction induced by upper abdominal surgery. Role of postoperative pain. Am Rev Respir Dis 1983, 128:899-903.

16. Aubrun F, Gazon M, Schoeffler M, Benyoub K: Evaluation of perioperative risk in elderly patients. Minerva Anestesiol 2012, 78:605-618.

17. Otis DR Jr., Johnson M, Pedley TJ, Kamm RD: Role of pulmonary surfactant in airway closure: a computational study. J Appl Physio/ 1993, 75:1323-1333.

18. Tusman G, Bohm SH, Warner DO, Sprung J: Atelectasis and perioperative pulmonary complications in high-risk patients. Curr Opin Anaesthesiol 2012, 25:1-10.

19. Arozullah AM, Daley J, Henderson WG, Khuri SF: Multifactorial risk index for predicting postoperative respiratory failure in men after major noncardiac surgery. The National Veterans Administration Surgical Quality Improvement Program. Ann Surg 2000, 232:242-253.

20. Smetana GW, Lawrence VA, Cornell JE: Preoperative pulmonary risk stratification for noncardiothoracic surgery: systematic review for the American College of Physicians. Ann Intern Med 2006, 144:581-595. 
21. Wrigge H, Zinserling J, Stuber F, von Spiegel T, Hering R, Wetegrove S, Hoeft A, Putensen C: Effects of mechanical ventilation on release of cytokines into systemic circulation in patients with normal pulmonary function. Anesthesiology 2000, 93:1413-1417.

22. Wrigge $H$, Uhlig $U$, Zinserling J, Behrends-Callsen E, Ottersbach G, Fischer M, Uhlig S, Putensen C: The effects of different ventilatory settings on pulmonary and systemic inflammatory responses during major surgery. Anesth Analg 2004, 98:775-781.

23. Determann RM, Wolthuis EK, Choi G, Bresser P, Bernard A, Lutter R, Schultz MJ: Lung epithelial injury markers are not influenced by use of lower tidal volumes during elective surgery in patients without preexisting lung injury. Am J Physiol Lung Cell Mol Physiol 2008, 294:L344-L350.

24. Treschan TA, Kaisers W, Schaefer MS, Bastin B, Schmalz U, Wania V, Eisenberger CF, Saleh A, Weiss M, Schmitz A, Kienbaum P, Sessler DI, Pannen B, Beiderlinden $\mathrm{M}:$ Ventilation with low tidal volumes during upper abdominal surgery does not improve postoperative lung function. $\mathrm{Br} J$ Anaesth 2012, 109:263-271.

25. Weingarten TN, Whalen FX, Warner DO, Gajic O Schears GJ, Snyder MR, Schroeder DR, Sprung J: Comparison of two ventilatory strategies in elderly patients undergoing major abdominal surgery. Br J Anaesth 2010 104:16-22.

26. Severgnini P, Selmo G, Lanza C, Chiesa A, Friegerio A, Bacuzzi A, Dionigi G, Novario R, Geroretti C, de Abreu MG, Schultz MJ, Jaber S, Futier E, Chiaranda $M$, Pelosi P: Protective mechanical ventilation during general anesthesia for open abdominal surgery improves postoperative pulmonary function. Anesthesiology 2013, 118:1307-1321.

27. Futier E, Constantin JM, Paugam-Burtz C, Pascal J, Eurin M, Neuschwander A, Marret E, Beaussier M, Gutton C, Lefrant JY, Allaouchiche B, Verzilli D, Leone M, De Jong A, Bazin JE, Pereira B, Jaber S, IMPROVE Study Group: A trial of intraoperative low-tidal-volume ventilation in abdominal surgery. N Eng/J Med 2013, 369:428-437.

28. Hemmes SN, Severgnini P, Jaber S, Canet J, Wrigge H, Hiesmayr M, Tschernko EM, Hollman MW Binnekade JM, Hedenstierna G, Putensen C, de Abreu MG, Pelosi P, Schultz MJ: Rationale and study design of PROVHILO - a worldwide multicenter randomized controlled trial on protective ventilation during general anesthesia for open abdominal surgery. Trials 2011, 12:111.

29. Fernandez-Perez ER, Keegan MT, Brown DR, Hubmayr RD, Gajic O: Intraoperative tidal volume as a risk factor for respiratory failure after pneumonectomy. Anesthesiology 2006, 105:14-18.

30. van der Werff YD, van der Houwen HK, Heijmans PJ, Duurkens VA, Leusink HA, van Heeswijk HP, de Boer A: Postpneumonectomy pulmonary edema. A retrospective analysis of incidence and possible risk factors. Chest 1997 111:1278-1284.

31. Cohen E: Management of one-lung ventilation. Anesthesiol Clin North America 2001, 19:475-495.

32. Wilson WCBJ: Anesthesia for thoracic surgery. In Miller's Anesthesia, 6th edn. Edited by Miller RD. Elsevier Churchill Livingstone, Philadelphia, 2005, pp 1894-1895.

33. Schilling T, Kozian A, Huth C, Bühling F, Kretzschmkar M, Welte T, Hachenberg $\mathrm{T}$ : The pulmonary immune effects of mechanical ventilation in patients undergoing thoracic surgery. Anesth Analg 2005, 101:957-965.

34. Licker M, Diaper J, Villiger Y, Spiliopoulos A, Licker V, Robert J, Tschopp JM: Impact of intraoperative lung-protective interventions in patients undergoing lung cancer surgery. Crit Care 2009, 13:R41.

35. Yang M, Ahn HJ, Kim K, Kim JA, Yi CA, Kim MG, Kim HJ:Does a protective ventilation strategy reduce the risk of pulmonary complications after lung cancer surgery?: a randomized controlled trial. Chest 2011, 139:530-537.
36. Michelet P, D'Journo XB, Roch A, Doddoli C, Marin V, Papazian L, Decamps I, Bregeon F, Thomas P, Auffray JP: Protective ventilation influences systemic inflammation after esophagectomy: a randomized controlled study. Anesthesiology 2006, 105:911-919.

37. De Somer F: End-organ protection in cardiac surgery. Minerva Anestesiol 2013, 79:285-293.

38. Butler J, Rocker GM, Westaby S: Inflammatory response to cardiopulmonary bypass. Ann Thorac Surg 1993, 55:552-559.

39. Wan S, LeClerc JL, Vincent JL: Inflammatory response to cardiopulmonary bypass: mechanisms involved and possible therapeutic strategies. Chest 1997, 112:676-692

40. Cremer J, Martin M, Redl H, Bahrami S, Abraham C, Graeter T, Haverich A, Schlag G, Borst HG: Systemic inflammatory response syndrome after cardiac operations. Ann Thorac Surg 1996, 61:1714-1720.

41. Wrigge H, Uhlig U, Baumgarten G, Menzenbach J, Zinserling J, Ernst M, Drömann D, Welz A, Uhliq S, Putensen C: Mechanical ventilation strategies and inflammatory responses to cardiac surgery: a prospective randomized clinical trial. Intensive Care Med 2005, 31:1379-1387.

42. Koner O, Celebi S, Balci H, Cetin G, Karaoglu K, Cakar N: Effects of protective and conventional mechanical ventilation on pulmonary function and systemic cytokine release after cardiopulmonary bypass. Intensive Care Med 2004, 30:620-626.

43. Sundar S, Novack V, Jervis K, Bender SP, Lerner A, Panzicas P, Mahmood F, Malhotra A, Talmor D: Influence of low tidal volume ventilation on time to extubation in cardiac surgical patients. Anesthesiology 2011, 114:1102-1110.

44. Zupancich E, Paparella D, Turani F, Munch C, Rossi A, Massaccesi S, Ranieri VM: Mechanical ventilation affects inflammatory mediators in patients undergoing cardiopulmonary bypass for cardiac surgery: a randomized clinical trial. J Thorac Cardiovasc Surg 2005, 130:378-383.

45. The Acute Respiratory Distress Syndrome Network: Ventilation with lower tidal volumes as compared with traditional tidal volumes for acute lung injury and the acute respiratory distress syndrome. N Engl J Med 2000, 342:1301-1308.

46. Amato MB, Barbas CS, Medeiros DM, Magaldi RB, Schettino GP, Lorenzi-Gilho G, Kairalla RA, Deheinzelin D, Munoz C, Oliveira R, Takagaki TY, Carvalho CR: Effect of a protective-ventilation strategy on mortality in the acute respiratory distress syndrome. N Engl J Med 1998, 338:347-354.

47. Reis MD, Gommers D, Struijs A, Dekker R, Mekel J, Feelders R, Lachmann B, Bogers AJ:Ventilation according to the open lung concept attenuates pulmonary inflammatory response in cardiac surgery. Eur $J$ Cardiothorac Surg 2005, 28:889-895.

48. Reis MD, Struijs A, Koetsier P, van Thiel R, Schepp R, Hop W, Klein J, Lachmann $B$, Bogers AJ, Gommers D: Open lung ventilation improves functional residual capacity after extubation in cardiac surgery. Crit Care Med 2005, 33:2253-2258

49. Chaney MA, Nikolov MP, Blakeman BP, Bakhos M: Protective ventilation attenuates postoperative pulmonary dysfunction in patients undergoing cardiopulmonary bypass. J Cardiothorac Vasc Anesth 2000, 14:514-518.

50. Wrigge $H$, Pelosi $P$ : Tidal volume in patients with normal lungs during general anesthesia: lower the better? Anesthesiology 2011, 114:1011-1013.

doi:10.1186/cc13777

Cite this article as: Coppola $S$, et al: Protective lung ventilation during general anesthesia: is there any evidence? Critical Care 2014, 18:210. 